\title{
Nanolayer formation on titanium by phosphonated gelatin for cell adhesion and growth enhancement
}

This article was published in the following Dove Press journal:

International Journal of Nanomedicine

2 September 2015

Number of times this article has been viewed

\author{
Xiaoyue Zhou ${ }^{1,2, *}$ \\ Shin-Hye Park ${ }^{1, *}$ \\ Hongli $\mathrm{Mao}^{3}$ \\ Takashi Isoshima' \\ Yi Wang ${ }^{2}$ \\ Yoshihiro Ito ${ }^{1,3}$ \\ 'Nano Medical Engineering \\ Laboratory, RIKEN, Wako, Saitama, \\ Japan; ${ }^{2}$ Department of Regenerative \\ Medicine, School of Pharmaceutical \\ Sciences, Jilin University, Changchun, \\ Jilin, People's Republic of China; \\ ${ }^{3}$ Emergent Bioengineering Materials \\ Research Team, RIKEN Center for \\ Emergent Matter Science, Wako, \\ Saitama, Japan \\ *These authors contributed equally \\ to this work
}

\begin{abstract}
Phosphonated gelatin was prepared for surface modification of titanium to stimulate cell functions. The modified gelatin was synthesized by coupling with 3-aminopropylphosphonic acid using water-soluble carbodiimide and characterized by ${ }^{31} \mathrm{P}$ nuclear magnetic resonance and gel permeation chromatography. Circular dichroism revealed no differences in the conformations of unmodified and phosphonated gelatin. However, the gelation temperature was changed by the modification. Even a high concentration of modified gelatin did not form a gel at room temperature. Time-of-flight secondary ion mass spectrometry showed direct bonding between the phosphonated gelatin and the titanium surface after binding. The binding behavior of phosphonated gelatin on the titanium surface was quantitatively analyzed by a quartz crystal microbalance. Ellipsometry showed the formation of a several nanometer layer of gelatin on the surface. Contact angle measurement indicated that the modified titanium surface was hydrophobic. Enhancement of the attachment and spreading of MC-3T3L1 osteoblastic cells was observed on the phosphonated gelatin-modified titanium. These effects on cell adhesion also led to growth enhancement. Phosphonation of gelatin was effective for preparation of a cell-stimulating titanium surface.
\end{abstract}

Keywords: phosphonated gelatin, surface modification, titanium, cell adhesion

\section{Introduction}

Titanium and titanium alloys are widely used in medical applications such as the replacement of hard tissues including bone, joints, and dental implants, because of their nontoxicity, good mechanical properties, and excellent resistance to corrosion. ${ }^{1}$ However, there is still a need to further investigate their biocompatibility including the interface between titanium and the biological tissue. Because of a lack of bonding of implants to juxtaposed tissues, current orthopedic implants have a variety of problems including infection, extensive inflammation, and overall poor osseointegration.

Therefore, many attempts have been made to modify the surface of titanium with functional or biological components to induce tissue responses to biomaterials and provide a set of powerful signals for cell growth and differentiation..$^{2-6}$ However, there are limited procedures for surface modification with biological molecules. To biologically modify metal surfaces, silane-based coupling methods have been conventionally employed to prepare an initial organic layer on the metal surface. ${ }^{7-10}$ However, in addition to physicochemical modification, ${ }^{11-13}$ recent biomimetic approaches inspired by underwater organisms for surface modification have been proposed by many studies. ${ }^{1423}$

3,4-Dihydroxyphenylalanine was identified in underwater adhesion proteins, and its simplified compound dopamine has been employed for biological modification
Correspondence: Yoshihiro Ito Nano Medical Engineering Laboratory, RIKEN, 2-I Hirosawa, Wako, Saitama 35I-0I98, Japan

Tel +8I 484674979

Fax +8I 484679300

Email y-ito@riken.jp submit your manuscript | www.dovepress.com

Dovepress

http://dx.doi.org// 0.2147/IJN.S82166
International Journal of Nanomedicine 2015:10 5597-5607 
of metal surfaces. ${ }^{20-22}$ In addition, as another non-canonical amino acid, phosphonated serine has been applied to underwater adhesion. ${ }^{23-25}$ Such phosphate groups have been found in the underwater adhesive proteins of the sandcastle worm and caddy silks, ${ }^{16,17}$ which interact specifically with a titanium surface. ${ }^{26-33}$ In previous studies, we have anchored various extracellular matrices and growth factors onto metal to provide a source of signals to continuously, stably, and efficiently stimulate cells to reconstitute damaged tissues during long-term regeneration. ${ }^{34-36}$ Therefore, it may be useful to prepare metal-anchored proteins using biomimetic methods for convenient surface modification.

The cell-adhesive protein gelatin has been employed for the chemical modification of titanium. ${ }^{8,37-40}$ Here, titaniumand cell-adhesive gelatin was prepared by chemical modification with phosphate groups as a biological approach to enhance cell functions on titanium surfaces. We found that the gelation temperature was reduced by the modification and time-of-flight secondary ion mass spectrometry (ToFSIMS) showed direct bonding between the phosphonated gelatin and the titanium surface. In addition, the modified surface promoted cell adhesion and spreading, as well as cell growth.

\section{Materials and methods \\ Materials}

Porcine gelatin (gelatin from porcine skin, Type A, G1890, IEP: 7-9) and 3-aminopropylphosphonic acid were purchased from Sigma-Aldrich (St Louis, MO, USA). 4-(4,6-Dimethoxy-1,3,5-triazin-2-yl)-4-methyl morpholinium chloride was purchased from Wako Pure Chemical Industries, Ltd (Tokyo, Japan). The osteoblast cell line MC-3T3L1 was provided by the RIKEN Cell Bank (Tsukuba, Japan) and maintained in Dulbecco's Modified Eagle's Medium (DMEM) (Sigma-Aldrich) supplemented with $10 \%$ fetal bovine serum (Moregate Inc., Brisbane, QLD, Australia). Trypsin (0.25\%)-EDTA (1 mmol) solution was purchased from Wako Pure Chemical Industries, Ltd (Tokyo, Japan).

A glass plate (15 $\mathrm{mm}$ in diameter and $1 \mathrm{~mm}$ thick) was coated with titanium by Osaka Vacuum Industrial Co., Ltd (Osaka, Japan) as described previously. ${ }^{10,11}$ Pure titanium was vacuum deposited on the plate by an electron beam of $400 \mathrm{~nm}( \pm 25 \%)$ in width. The thickness of the titanium layer was controlled to maintain the transparency for optical microscopic observations. The plate was then cleaned by ultrasonication nine times in ultrapure water and dried with heated gas.

\section{Phosphonation of gelatin}

Phosphonated gelatin was synthesized as shown in Figure 1. The gelatin solution was dissolved at $40^{\circ} \mathrm{C}$ in water at $20 \mathrm{mg} / \mathrm{mL}$ and stirred for 1 hour at $40^{\circ} \mathrm{C}$. 3-Aminopropylphosphonic acid (12.5 mM) and then the 4-(4,6-dimethoxy-1,3,5-triazin2-yl)-4-methyl morpholinium chloride ${ }^{41,42}$ coupling reagent ( $4 \mathrm{mM})$ were added to the solution. After 48 hours of stirring

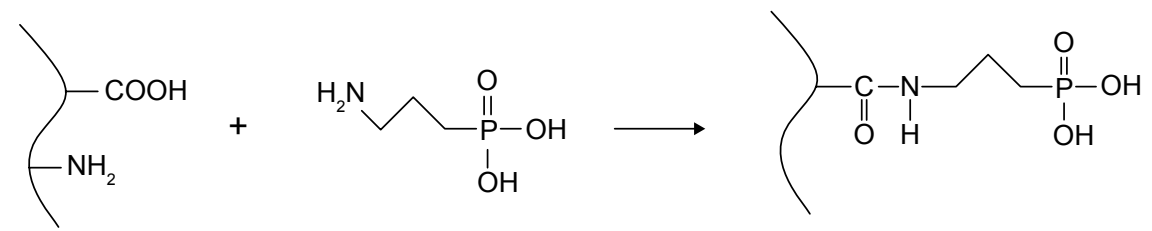

Gelatin

3-Aminopropylphosphonic acid

Phosphonated gelatin

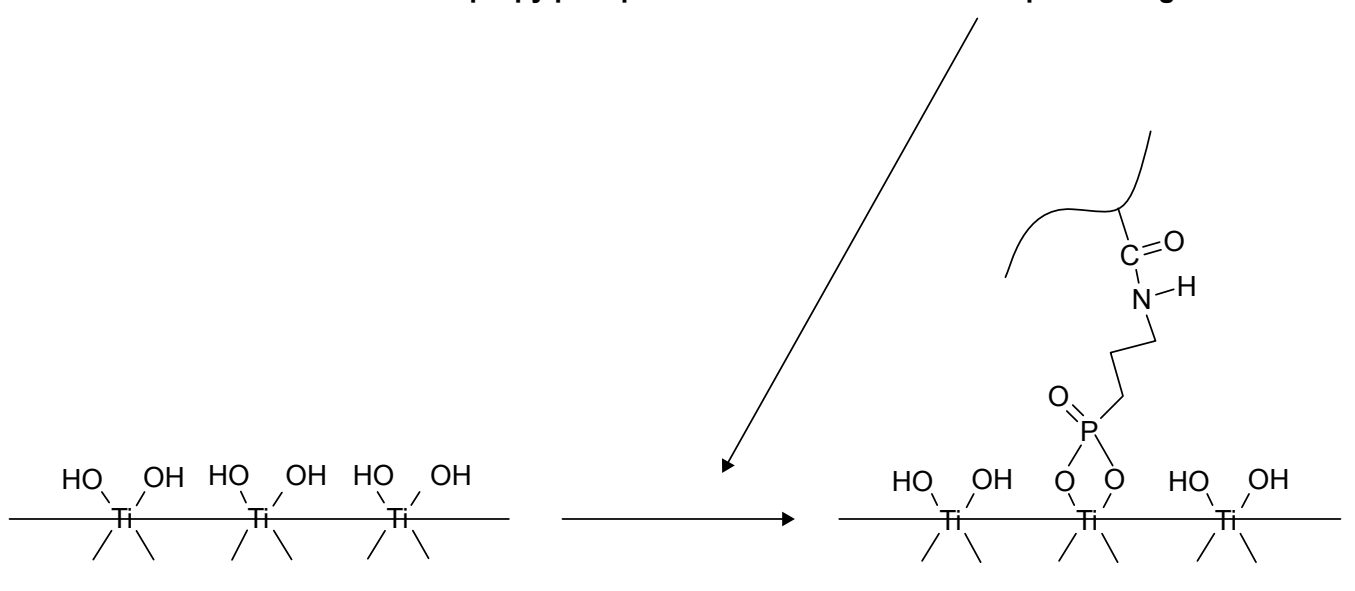

Titanium

Figure I Preparation of phosphonated gelatin. 
at $40^{\circ} \mathrm{C}$, the resulting solution was dialyzed using a seamless cellulose tube (cutoff molecular weight of 10,000 D). The dialyzed phosphonated gelatin was finally freeze dried in a vacuum to obtain a white solid (40\% yield) used in this study as the phosphonated gelatin.

${ }^{31} \mathrm{P}$ nuclear magnetic resonance (NMR) spectra of 3-aminopropylphosphonic acid and phosphonated gelatin were recorded on a $400-\mathrm{MHz}$ NMR spectrometer (JEOL 400, Akishima, Japan).

For circular dichroism measurement using a J-720 spectropolarimeter (Jasco, Hachioji, Japan), we prepared 0.01\% gelatin and $0.01 \%$ phosphonated gelatin. Samples of $250 \mu \mathrm{L}$ were analyzed using a $1 \mathrm{~mm}$ cuvette (scan type: continuous; scan speed: $50 \mathrm{~nm} / \mathrm{min}$; response time: 2.0 seconds; bandwidth: $1.0 \mathrm{~nm}$ ). Each sample was measured six times to obtain average spectra.

Quartz crystal microbalance measurement Adsorption of phosphonated gelatin at various concentrations on the titanium-coated substrate was measured at $22^{\circ} \mathrm{C}$ using a quartz crystal microbalance (QCM) with dissipation monitoring (Meiwafosis Co., Ltd, Tokyo, Japan). Specifically, Milli-Q water was allowed to run until stabilization of the baseline. The sample was then run for 3 minutes at approximately $65 \mu \mathrm{L} / \mathrm{min}$. The pump was turned off for 15 minutes, and finally the substrate was washed by running Milli-Q water. For each concentration of phosphonated gelatin, at least three measurements were obtained to calculate the average value.

\section{Surface characterization}

ToF-SIMS was performed using a PHI TRIFT V nanoTOF (ULVAC-PHI, Chigasaki, Kanagawa, Japan). For analysis, the ion beam was $30 \mathrm{kV} \mathrm{Bi}^{3++} 2.9 \mathrm{nA} \mathrm{DC}(-$ SIMS) and $30 \mathrm{kV}$ $\mathrm{Bi}^{3++} 8.0 \mathrm{nA}$ DC (+SIMS). The scanning areas were $100 \times 100 \mu \mathrm{m}(-$ SIMS) and $200 \times 200 \mu \mathrm{m}(+$ SIMS). Pulse widths of both -SIMS and +SIMS were 12 nanoseconds. The flame numbers of -SIMS and +SIMS were $62(200 \mu \mathrm{m}$ square: $\left.1 \times 10^{12} / \mathrm{cm}^{2}\right)$ and $18\left(200 \mu \mathrm{m}\right.$ square: $\left.2 \times 10^{11} / \mathrm{cm}^{2}\right)$, respectively.

The thickness of the phosphonated gelatin layer was measured using an ellipsometer (M-2000UI; JA Woollam Co., Lincoln, NE, USA) at three different incident angles $\left(50^{\circ}, 60^{\circ}\right.$, and $\left.70^{\circ}\right)$. First, the titanium-coated glass substrates were measured and analyzed to determine the thickness and material parameters of each substrate, followed by coating with phosphonated gelatin and measurement by ellipsometry. The thickness of the phosphonated gelatin layer was determined by assuming a standard Cauchy optical dispersion model for the layer in the spectral range of $600-1,500 \mathrm{~nm}$, as follows:

$$
n(\lambda)=1.45+0.01 / \lambda
$$

where $n$ is the refractive index and $\lambda$ is the wavelength in $\mathrm{nm}$. Because the thickness was as small as a few nm, Cauchy optical dispersion parameters were not fit.

The surface morphology of the samples was observed using an atomic force microscope (AFM; MFP-3D, Asylum Research, Co., Goleta, CA, USA). The images were taken in $\mathrm{AC}$ (non-contact) mode using an AFM tip (NCH-W; NanoWorld AG, Neuchatel, Switzerland) in dry, atmospheric pressure conditions. The scan area was $1 \mu \mathrm{m} \times 1 \mu \mathrm{m}$, and the scan rate was $1 \mathrm{~Hz}$. Surface topological images were corrected for offset and linear tilt.

Surface wettability was determined by observing the water and glycerol contact angle on the discs. Water droplets of $1 \mu \mathrm{L}$ were placed on the discs (untreated and treated titanium), and images of the droplets were captured at 3 seconds after placement. The water contact angle was measured at $25^{\circ} \mathrm{C}$ using a contact-angle meter (Kyowa Interface Science Co., Tokyo, Japan). All contact angles were determined by averaging ten different point values measured on each surface.

\section{Cell culture}

MC-3T3L1 cells were cultured in DMEM supplemented with $10 \%$ fetal bovine serum at $37^{\circ} \mathrm{C}$ in $95 \%$ humidified air with $5 \% \mathrm{CO}_{2}$. The cells were washed using $10 \mathrm{~mL}$ phosphatebuffered saline and harvested with $0.25 \%$ trypsin in $1 \mathrm{mM}$ EDTA for 3 minutes at $37^{\circ} \mathrm{C}$. The recovered cells were resuspended in medium for subsequent in vitro examination. The cell suspension was added to 24 -well, polystyrene tissue culture plates ( $1 \mathrm{~mL}$ per well, $8 \times 10^{3}$ cells per $\mathrm{mL}$ ), each well of which contained sample plates that had been disinfected twice with $70 \%$ ethanol and then washed with sterilized $\mathrm{H}_{2} \mathrm{O}$. The cells were cultured in a $5 \% \mathrm{CO}_{2}$ atmosphere at $37^{\circ} \mathrm{C}$ for 30 minutes, 1 hour, 2 hours, and 4 days. Cell growth was determined using a cell counting kit (CCK-8, Dojindo Molecular Technologies, Inc., Kumamoto, Japan). Cell spreading was estimated according to the round and non-round shape ratio by observation under a phase-contrast microscope (Olympus CKX 41; Olympus, Hachioji, Japan).

\section{Statistical analysis}

Independent experiments were performed at least three times. Triplicate samples were analyzed in each experiment and representative data are shown. The significance of the data 
obtained from control and treated groups was statistically assessed by paired Student's $t$-tests with $P$-values of less than 0.05 considered to be significant.

\section{Results and discussion Preparation of phosphonated gelatin}

Gelatin is a protein produced by acid or alkaline processing of collagen and is a heterogeneous mixture of single- and multi-stranded polypeptides each with an extended lefthanded proline helix conformation and containing 50-1,000 amino acids. It consists of various $\alpha$-chains $(\sim 100 \mathrm{kDa})$, $\beta$-chains $(\sim 240 \mathrm{kDa})$, and $\gamma$-chains $(\sim 400 \mathrm{kDa}){ }^{43}$ The distribution of these chains is determined by the hydrolysis process. $^{43}$

In this study, elemental analysis showed that the prepared phosphonated gelatin contained $0.4 \mathrm{wt} \%$ of phosphorus. Considering that porcine gelatin has $11.4 \mathrm{wt} \%$ of carboxyl groups of glutamic acid (4.2\%) and aspartic acid (7.2\%), we concluded that about $14 \%$ of these groups were coupled with 3-aminopropylphosphonic acid. We had previously incorporated azidophenyl or furan groups into gelatin in a similar manner, and found that the contents were $84 \%{ }^{44}$ and near $100 \%{ }^{45}$ respectively. The low reactivity with phosphate was considered to be caused by ionic repulsion of the phosphate group. Similarly, the incorporation yield of 4-phosphonobutyric acid into gelatin was also low as reported previously. ${ }^{24}$

Figure 2 shows the ${ }^{31} \mathrm{P}$ peaks of the uncoupled phosphonic acid and phosphonated gelatin. Both peaks were located between 15 and $30 \mathrm{ppm}$ where phosphonate groups are ascribable. ${ }^{46}$ The peak of 3-aminopropylphosphonic acid observed at less than $25 \mathrm{ppm}$ shifted to a higher peak by about 2 ppm after incorporation into gelatin.

There were some differences in the elution patterns after phosphonation in the gel permeation chromatography (GPC) results of unmodified and phosphonated gelatin (data not

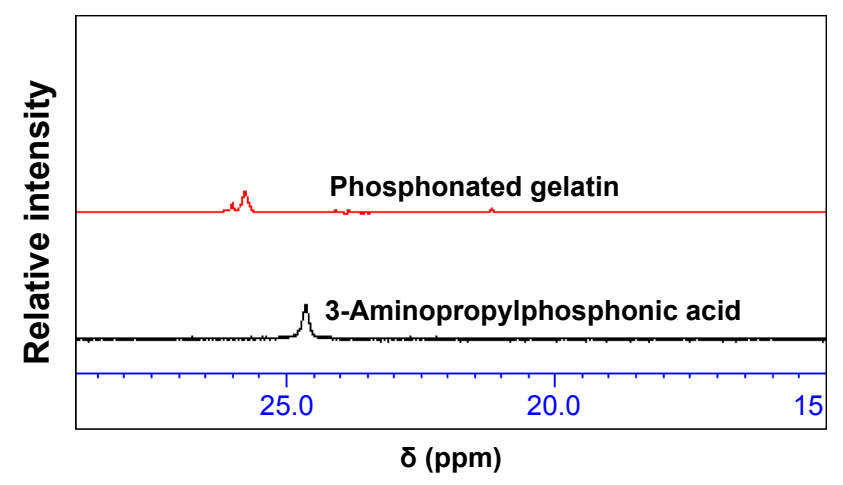

Figure $2{ }^{31} \mathrm{P}$ NMR spectra of 3-aminopropylphosphonic acid and phosphonated gelatin in the presence of phosphoric acid as the standard (0 ppm). Abbreviation: ${ }^{31} \mathrm{P}$ NMR, ${ }^{31} \mathrm{P}$ nuclear magnetic resonance. shown). According to the standard calibration using proteins, the main peak around a retention time of 18.2 minutes corresponded to a molecular weight of about $50 \mathrm{kDa}$. Considering that there was no reduction in the molecular weight, phosphonation may induce a change in molecular extension.

Circular dichroism spectra of unmodified and phosphonated gelatin are shown in Figure 3. Although Gopal et a ${ }^{47}$ reported some specific conformations of gelatin, we observed no specific conformation. This result was consistent with a previous report by Zhang et al. ${ }^{48}$ The almost identical spectra of unmodified and phosphonated gelatin demonstrated that phosphonation did not induce a conformational change in the gelatin.

Interestingly, the gelation behavior of phosphonated gelatin was very different from that of unmodified gelatin. As shown in Figure 4, when the temperature decreased from $37^{\circ} \mathrm{C}$ to $25^{\circ} \mathrm{C}, 3 \%$ unmodified gelatin solution formed gel, however, the $3 \%$ phosphonated gelatin remained the solution state. As shown in Figure 5, unmodified gelatin became turbid below $32.5^{\circ} \mathrm{C}$, while the modified gelatin was transparent and did not form a gel even below $25^{\circ} \mathrm{C}$. Incorporation of a small amount of phosphonic acid led to a drastic change in the gelatin temperature. It is known that the low gelation temperature of fish gelatin is due to the low content of proline and hydroxyproline. ${ }^{49}$ In this study, the incorporation of strong acidic groups (phosphonic acid) was considered to reduce the gelation temperature.

Because the unmodified gelatin was not soluble in water at room temperature, further experiments were performed only on phosphonated gelatin.

\section{Adsorption behavior}

To investigate direct bonding between titanium and phosphonate groups in the modified gelatin, ToF-SIMS

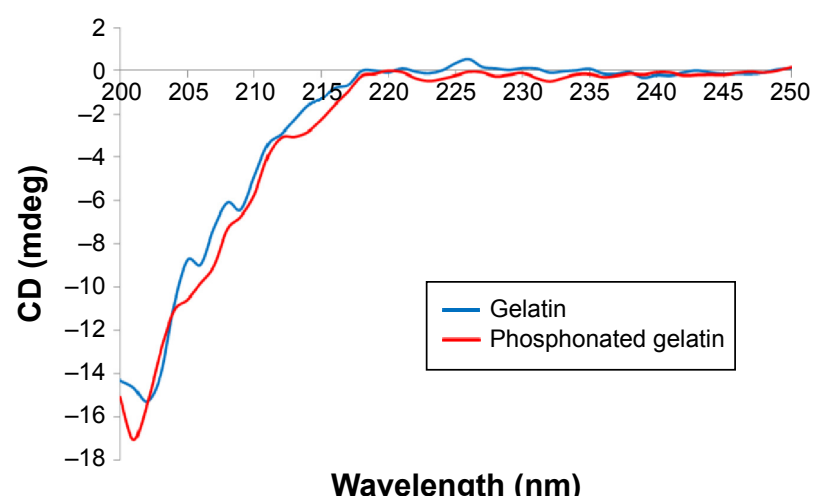

Figure $3 \mathrm{CD}$ spectra of unmodified and phosphonated gelatin. Note: The concentrations were $0.01 \mathrm{wt} \%$. Abbreviation: $\mathrm{CD}$, circular dichroism. 


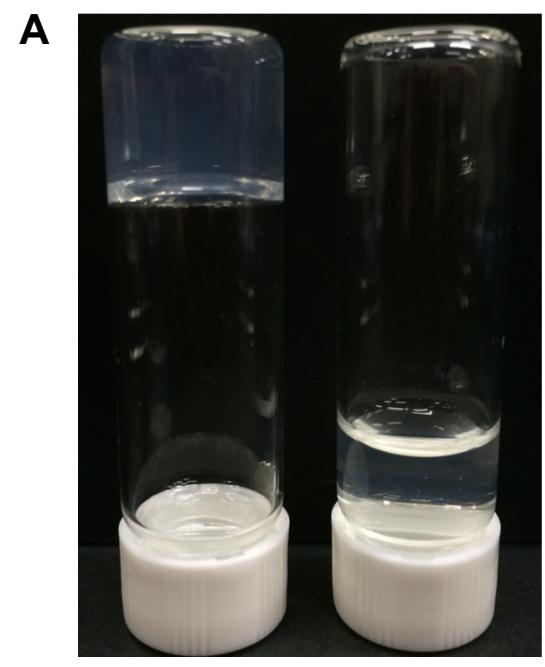

$25^{\circ} \mathrm{C}$
B

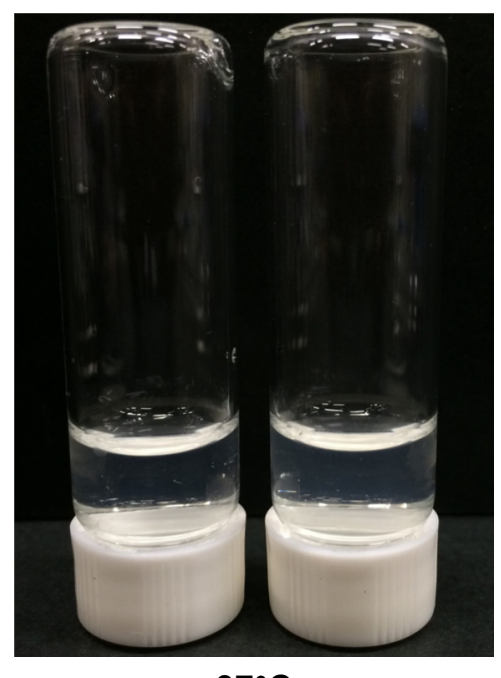

$37^{\circ} \mathrm{C}$

Figure 4 Photos of unmodified (left vial) and phosphonated gelatin (right vial) at $25^{\circ} \mathrm{C}(\mathbf{A})$ and $37^{\circ} \mathrm{C}$ (B).

Note: The concentrations were $3 \mathrm{wt} \%$.

measurements were obtained as shown in Figure 6. Peaks ascribed to Ti- $\mathrm{P}_{2}-\mathrm{O}_{6}$, Ti- $\mathrm{P}_{2}-\mathrm{O}_{7} \mathrm{H}$, and $\mathrm{Ti}-\mathrm{P}_{3}-\mathrm{O}_{6} \mathrm{H}_{2}$ were detected. The phosphonated gelatin preferentially adsorbed to the titanium surface through direct bonding. The phosphonate in gelatin was considered to be concentrated at the interface with titanium. Similarly, Adden et $\mathrm{al}^{32}$ and Viornery et $\mathrm{al}^{33}$ also investigated the interactions of phosphonic acid linked to organic compounds with titanium by ToFSIMS, and found strong indications of the formation of a chemical link, such as a Ti-O-P bond, between titanium and phosphonic acid molecules. According to Hotchkiss et $\mathrm{al}^{50}$ monolayers formed by phosphonic acids on metal oxide are more resistant to hydrolysis than those formed by silanes or carboxylic acids. The presence of three oxygen atoms is considered to allow covalent binding of phosphonic acid to an oxide surface in either monodentate, bidentate, or tridentate modes. ${ }^{50}$
Adsorption of phosphonated gelatin was measured by QCM (Figure 7). The adsorption was saturated at a phosphonated gelatin concentration of $3 \%$ with a real mass around $600 \mathrm{ng} / \mathrm{cm}^{2}$. Assuming that the molecular weight of phosphonated gelatin is $50 \mathrm{kDa}, 1.2 \times 10^{12}$ molecules of phosphonated gelatin were adsorbed per $\mathrm{cm}^{2}$ of titanium surface. Furthermore, assuming that the width of the phosphonated gelatin molecules is $\sim 1.5 \mathrm{~nm}$ and the length is $\sim 0.3 \mu \mathrm{m}$, one layer corresponded to around $2.2 \times 10^{11}$ molecules per $\mathrm{cm}^{2}$ for side-on adsorption and $4.4 \times 10^{13}$ molecules per $\mathrm{cm}^{2}$ for end-on adsorption. Collectively, the QCM results suggest that multi-layers were formed by side-on adsorption of the phosphonated gelatin molecules and less than one layer was formed by end-on adsorption. Assuming that the density of phosphonated gelatin is $1.2 \mathrm{~g} / \mathrm{cm}^{3}$, which is a typical value for organic materials, $600 \mathrm{ng} / \mathrm{cm}^{2}$ corresponds to $5 \mathrm{~nm}$ in thickness.

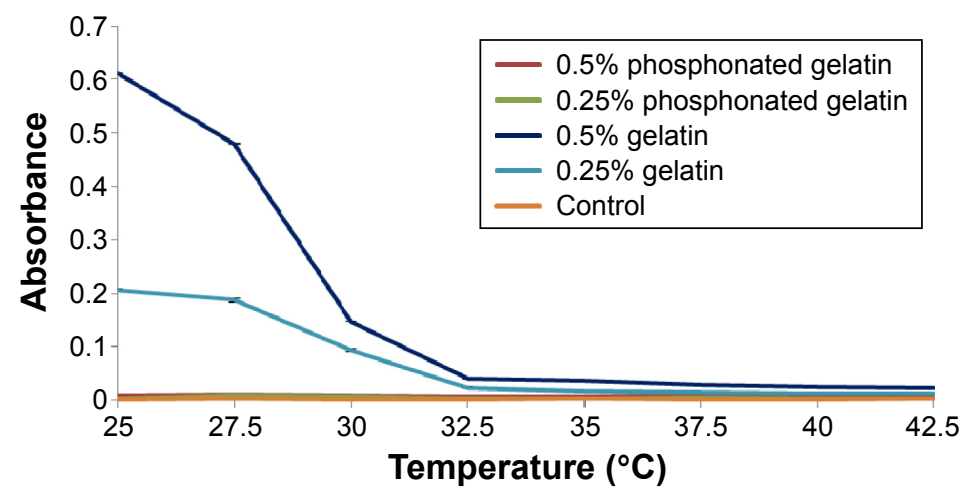

Figure 5 Temperature-dependent turbidity of solutions of unmodified and phosphonated gelatin. Note: Wavelength: $600 \mathrm{~nm}, \mathrm{n}=3$. 

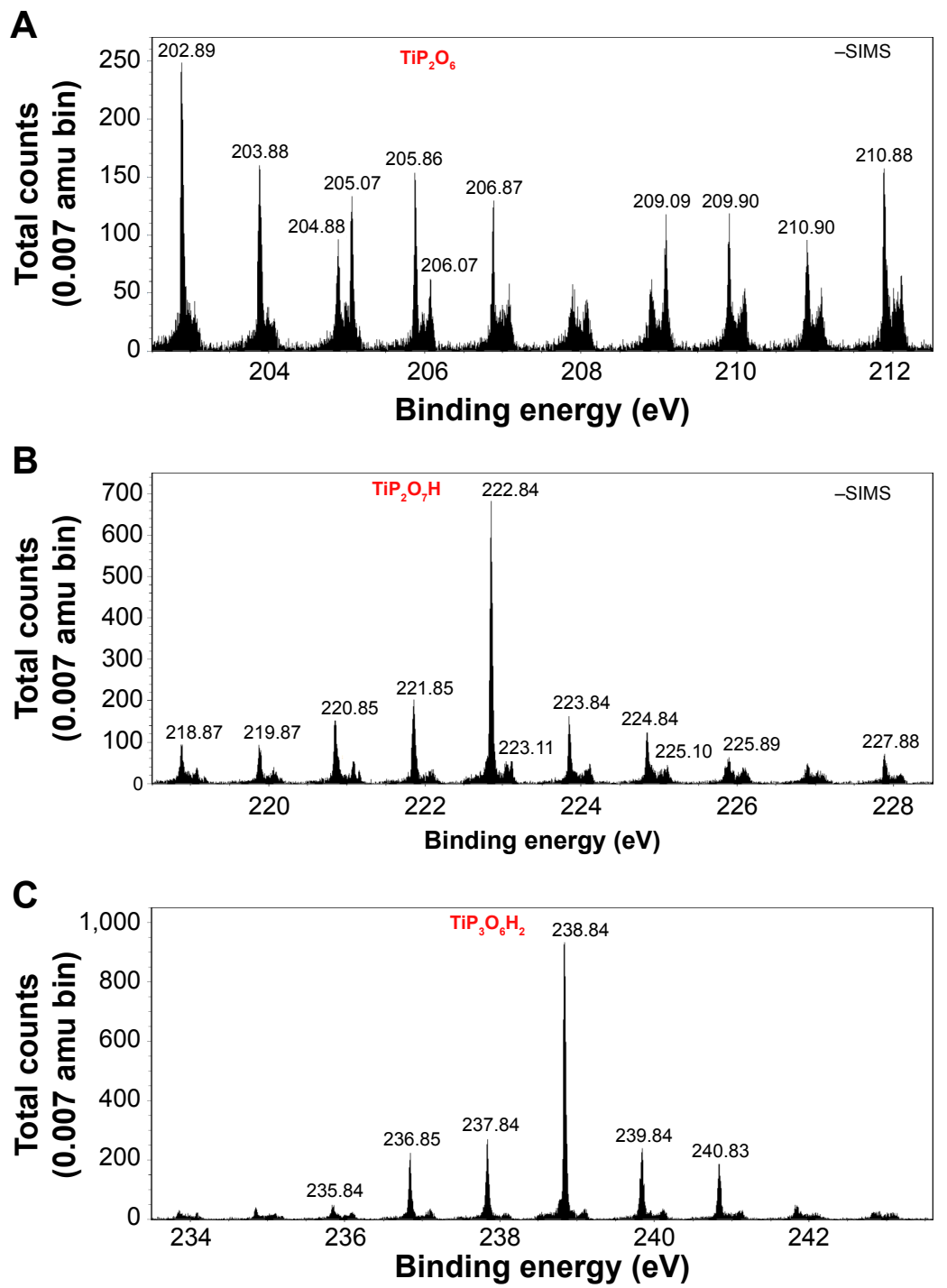

Figure 6 Negative ToF-SIMS results in the (A) $200.5-212.5 \mathrm{~m} / \mathrm{z}$, (B) $218.5-228.5 \mathrm{~m} / \mathrm{z}$, and (C) $233.5-243.5 \mathrm{~m} / \mathrm{z}$ region of the phosphonated gelatin-coated titanium surface.

Abbreviations: ToF-SIMS, time-of-flight secondary ion mass spectrometry; amu bin, binding energy per atom mass unit.

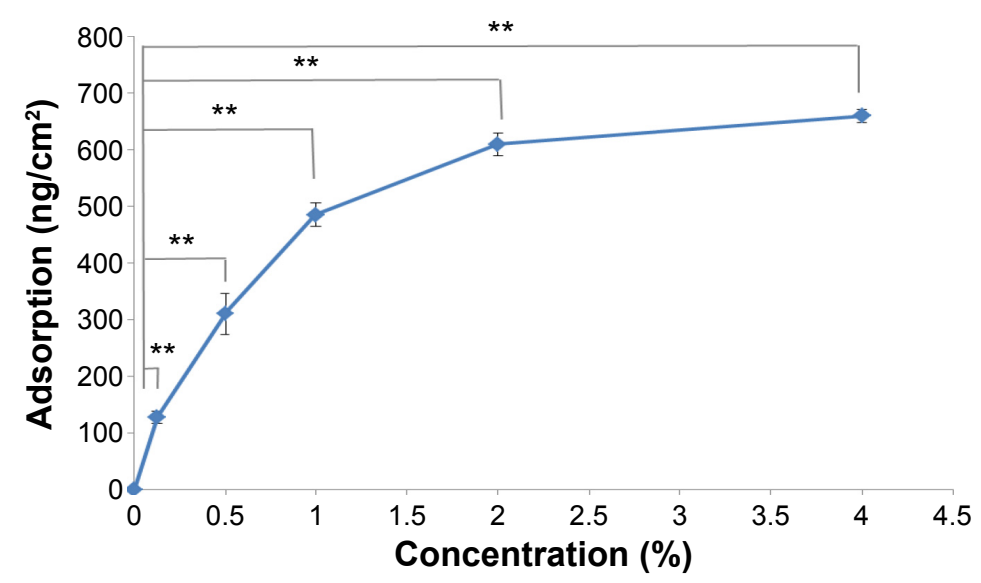

Figure $7 \mathrm{QCM}$ results for phosphonated gelatin adsorbed on the titanium surface. Note: $* * P<0.01$.

Abbreviation: QCM, quartz crystal microbalance. 
AFM observations indicated that a rough surface was formed by the bound gelatin (Figure 8). The roughness presented insignificant difference between different concentration ( $\mathrm{Ra}=1.4,1.1$, and $1.4 \mathrm{~nm}$ for gelatin concentration of $0.25 \%, 0.5 \%$, and $3 \%$, respectively). The images show particle-like structures with a diameter of a few to several tens of nm. This observation suggests that, although the solution of phosphonated gelatin was transparent at room temperature, some nanoscale gel (nanogel) formed on the surface. However, the particles seem not fully covering the surface, which can also be seen from the cross-sectional profiles in Figure 8. In addition,
A
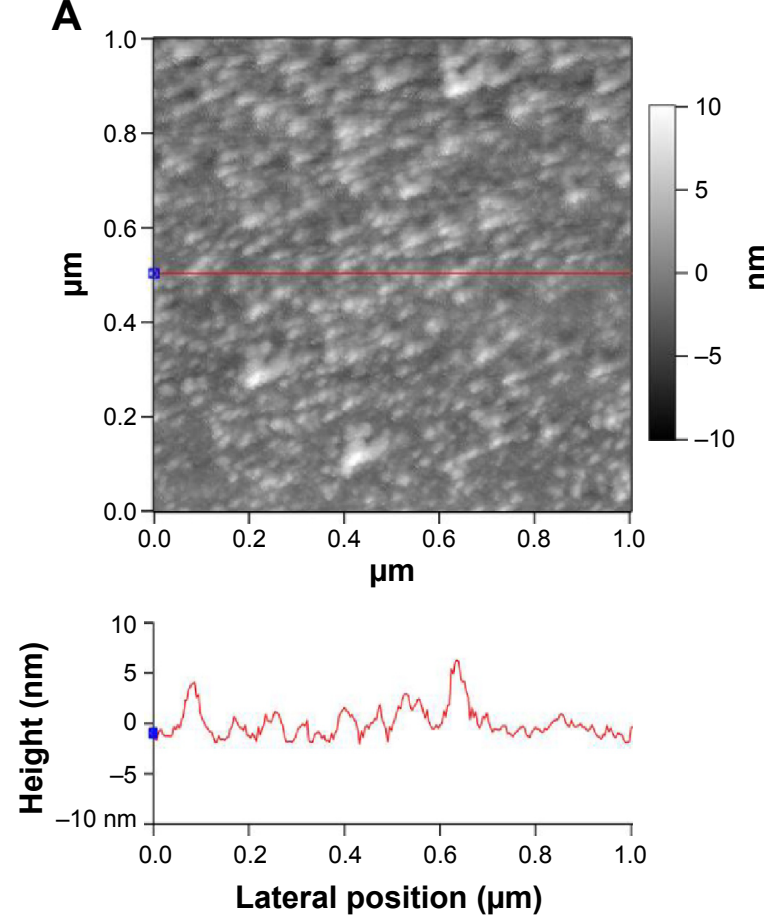

B
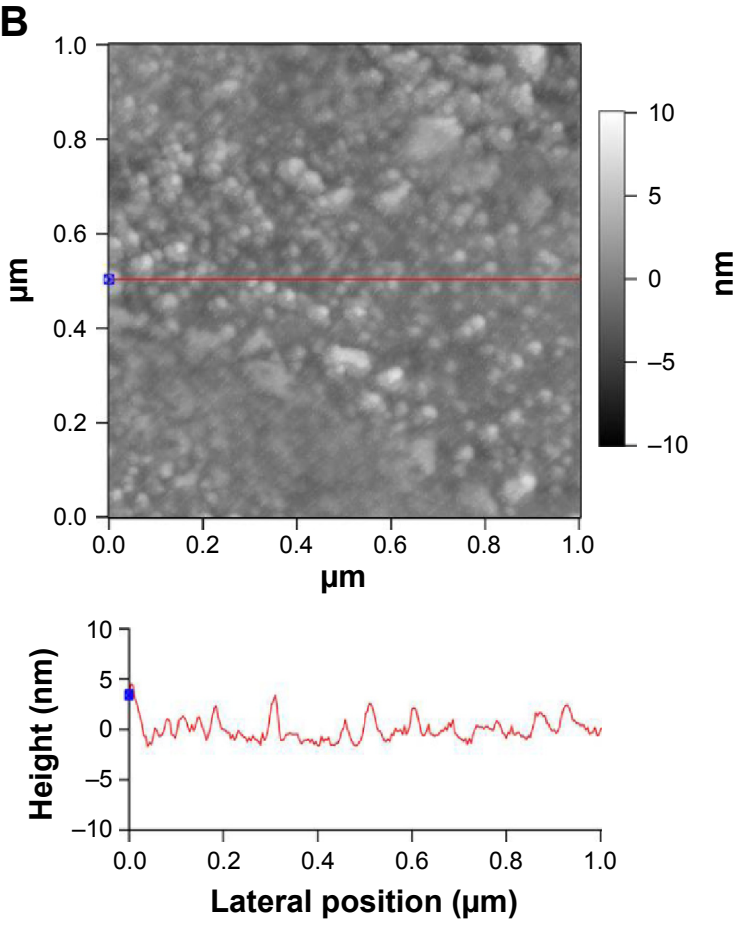
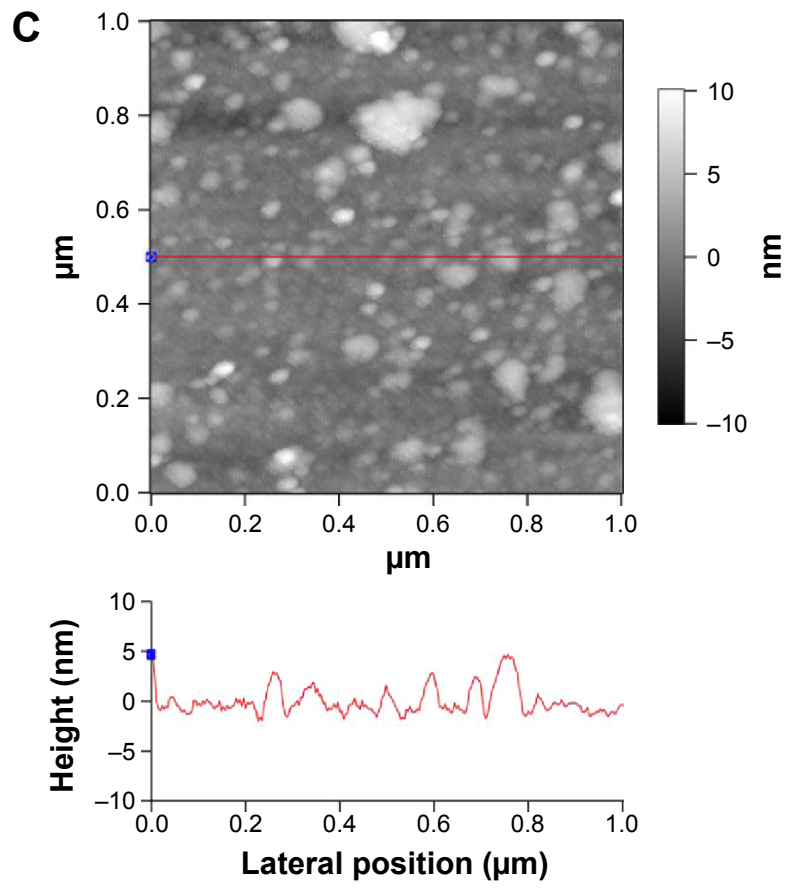

Figure 8 AFM topological images and cross-sectional surface profiles of titanium surfaces coated with (A) $0.25 \%$, (B) $0.5 \%$, and (C) $3 \%$ phosphonated gelatin. Each crosssectional surface profile (bottom) was taken at the red line in the corresponding topological image. Abbreviation: AFM, atomic force microscope. 


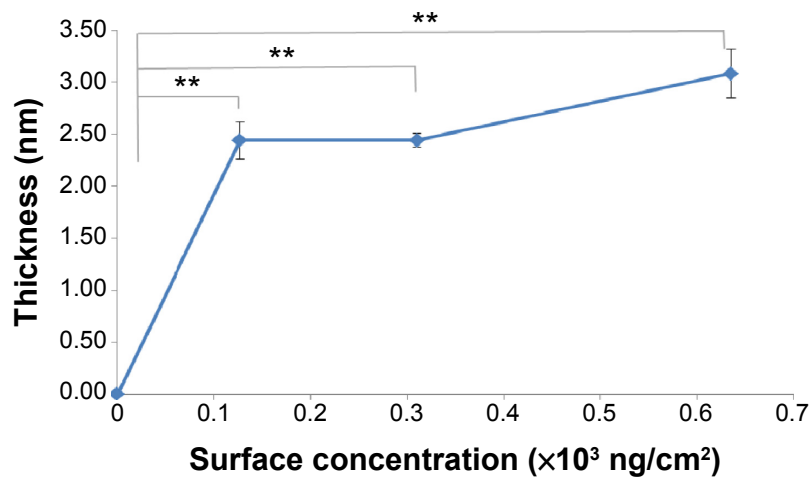

Figure 9 Thickness of phosphonated gelatin layers on titanium measured by ellipsometry.

Note: $* * P<0.01$.

surface roughness $(1.1-1.4 \mathrm{~nm})$ is slightly smaller than the thickness obtained by ellipsometry $(\sim 2.5 \mathrm{~nm}$ as shown in Figure 9). Although the thickness is not a precise film thickness but an averaged one, these results indicate that the gelatin forms fully covering layer on the substrate, on top of which some nanogel particles exists. The thickness of $\sim 2.5 \mathrm{~nm}$ obtained by ellipsometry was on the same order of magnitude as the QCM results.

Figure 10 shows the water and glycerol contact angle of the titanium surface coated with various concentrations of

1 hour

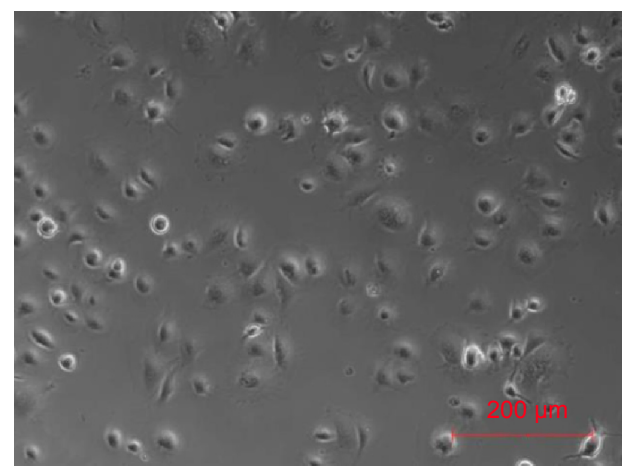

Control

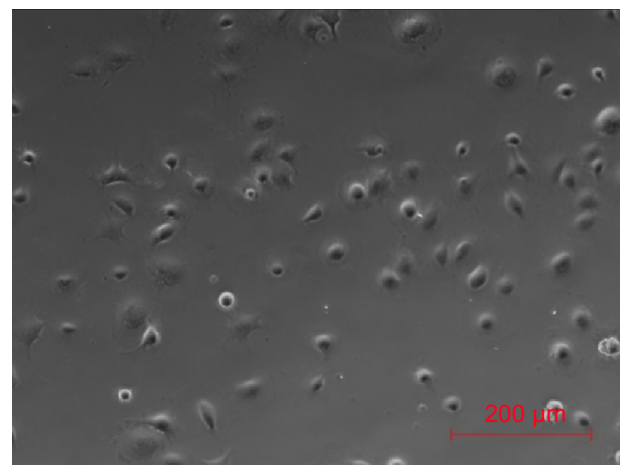

$2.5 \%$ phosphonated gelatin

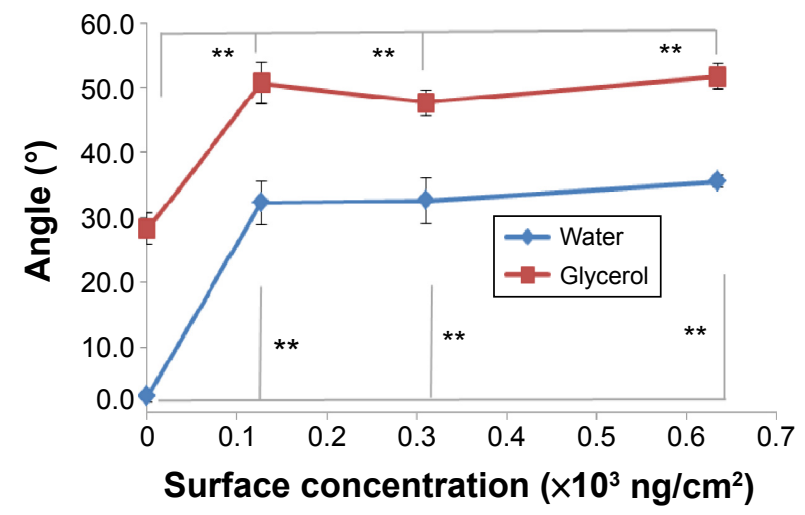

Figure 10 Water and glycerol contact angle of the titanium surface treated with the phosphonated gelatin.

Notes: $\mathrm{n}=10$, error bars indicate the standard deviation. $* * \mathrm{p}<0.01$.

unmodified and phosphonated gelatin. The results showed that the water contact angles of the titanium surface treated with phosphonated gelatin showed higher water contact angles than the untreated surface. The attachment to the surface of phosphonated gelatin significantly reduced the hydrophilicity of the titanium surface.

\section{Cell adhesion and growth}

Figure 11 shows cells adhered on the uncoated and phosphonated gelatin-coated titanium surface. Using titanium-deposited
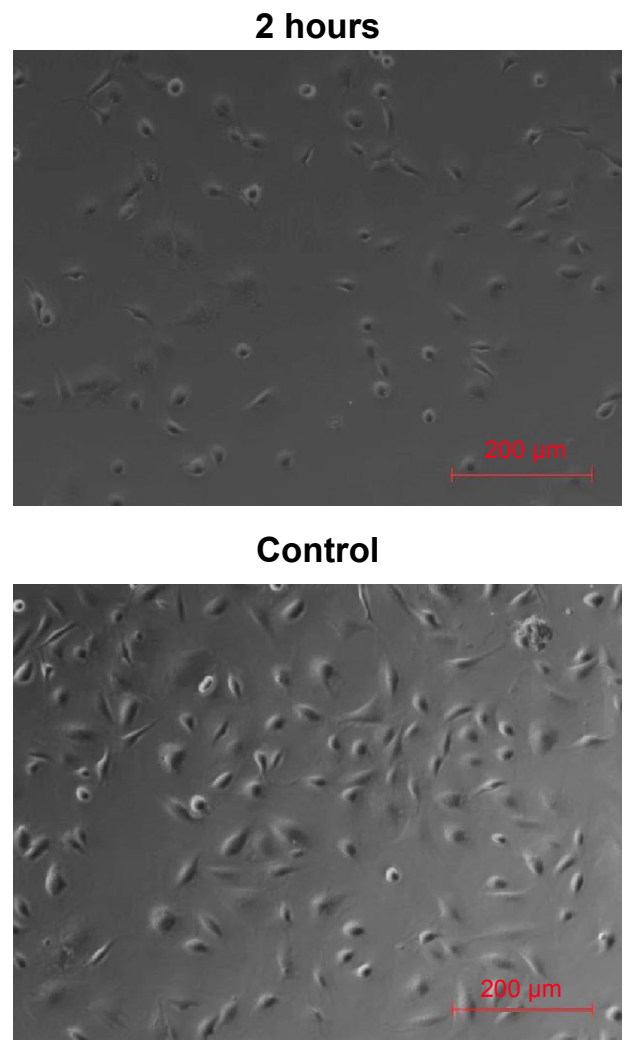

$2.5 \%$ phosphonated gelatin

Figure I I Micrographs of adhered cells on the phosphonated gelatin-coated titanium surface. 
glass discs, it was possible to observe the adhered cells by optical microscopy. The phosphonated gelatin-coated surface increased the spreading of cells over time. Figure 12 shows the number of adhered cells, as well as cell spreading and growth on the phosphonated gelatin-treated titanium surfaces. The spreading and growth on bare titanium discs was regarded
$100 \%$. The results indicated that phosphonation did not reduce the capacity of gelatin to support cell adhesion and spreading, and the enhancement of cell adhesion and spreading increased with the increase in the concentration of bound phosphonated gelatin on the surface. Lim et a ${ }^{38}$ also reported that conjugation of gelatin increases the adhesion and spreading of cells

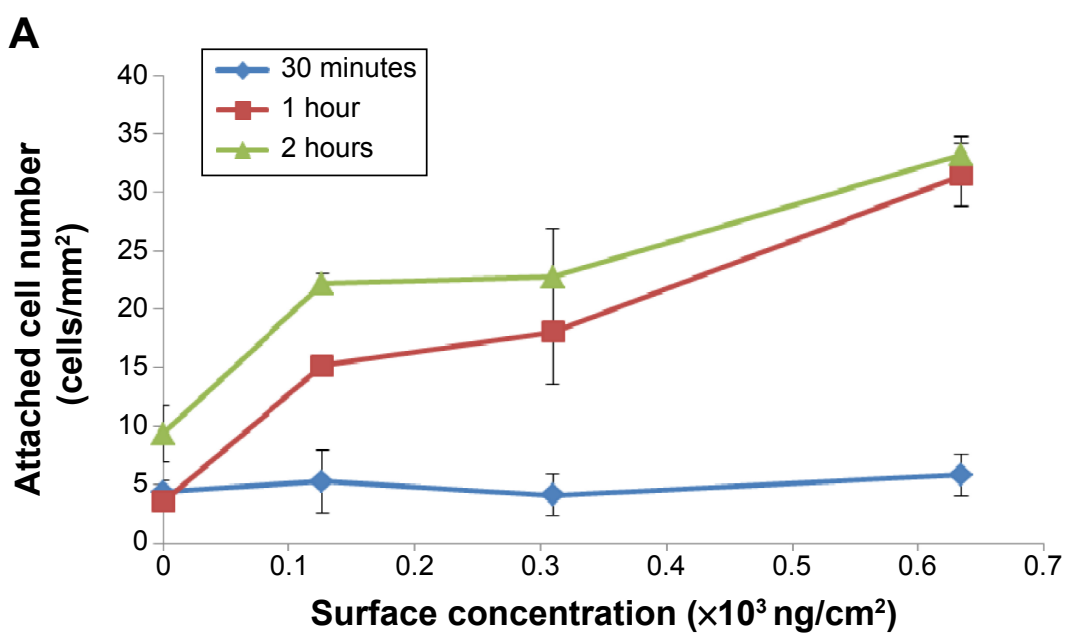

B
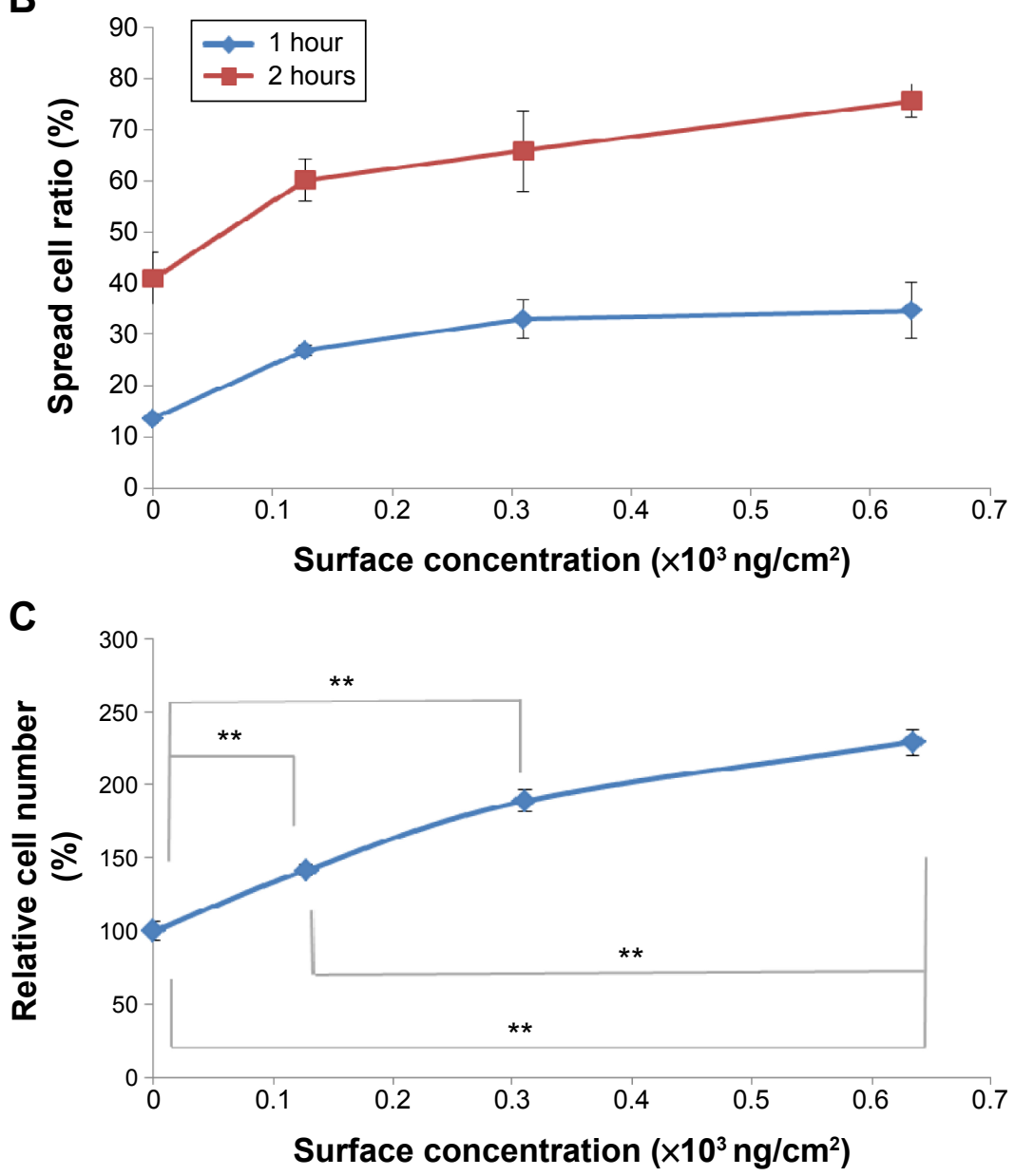

Figure 12 Cell culture results on titanium surfaces treated with phosphonated gelatin.

Notes: (A) Adhesion, (B) spreading, and (C) growth (after 4 days) of MC-3T3LI cells on titanium surfaces treated with phosphonated gelatin. $\mathrm{n}=3$, error bars indicate the standard deviation. $* * P<0.01$. 
on hydrogel surfaces. Hou et $\mathrm{al}^{51}$ also showed a significant enhancement of endothelial cell adhesion and proliferation on gelatin-modified surfaces. It is known that the surface hydrophilicity does not directly relate with cell attachment. $\mathrm{Ikada}^{52}$ reported moderate hydrophilicity was the best for cell attachment. For example, very hydrophilic surface like hydrogel reduces cell attachment. The gelatin modification is considered to provide moderate hydrophilicity on the surface. Taken together, these results indicated that the phosphonation enhanced the binding of gelatin onto titanium without losing the original cell adhesion or growth enhancement properties.

\section{Conclusion}

We succeeded in preparing phosphonated gelatin for surface modification of a titanium surface. The phosphonation enhanced the binding affinity of gelatin for the titanium surface and enhanced the attachment of MC-3T3L1 osteoblastic cells to the treated surfaces. Phosphonation of gelatin was effective for preparation of a cell-adhesive titanium surface and enabled coating at room temperature.

\section{Acknowledgments}

HM and YI thank Drs Naoki Kawazoe and Guoping Chen at National Institute of Materials Sciences (NIMS) for use of the equipment for QCM. A part of this work was supported by NIMS microstructural characterization platform (NMCP) as a program of "Nanotechnology Platform" of the Ministry of Education, Culture, Sports, Science and Technology (MEXT), Japan. We are grateful to Dr Hideo Iwai for performing ToF-SIMS measurement. This work was supported by Japan Society for the Promotion of Science KAKENHI Grant No 22220009.

\section{Disclosure}

The authors report no conflicts of interest in this work.

\section{References}

1. Brunette DM, Tengvall P, Textor M, Thomsen P, editors. Titanium in Medicine: Material Science, Surface Science, Engineering, Biological Responses, and Medical Application. Berlin: Springer Verlag; 2011.

2. Aninwene GE 2nd, Yao C, Webster TJ. Enhanced osteoblast adhesion to drug-coated anodized nanotubular titanium surfaces. Int J Nanomedicine. 2008;3(2):257-264.

3. Joddar B, Ito Y. Biological modifications of materials surfaces with proteins for regenerative medicine. J Mater Chem. 2011;21: 13737-13755.

4. Hanawa T. A comprehensive review of techniques for biofunctionalization of titanium. J Periodontal Implant Sci. 2011;41(6):263-272.

5. Zhou D, Ito Y. Inorganic material surfaces made bioactive by immobilizing growth factors for hard tissue engineering. RSC $A d v$. 2013;3: 11095-11106.

6. Ito Y, Tada S. Bio-orthogonal and combinatorial approaches for design of binding growth factors. Biomaterials. 2013;34(31):7565-7574.
7. Dubruel P, Vanderleyden E, Bergada M, et al. Comparative study of silanisation reactions for the biofunctionalisation of Ti-surfaces. Surf Sci. 2006;600(12):2562-2571.

8. Van Vlierberghe S, Vanderleyden E, Boterberg V, Dubruel P. Gelatin functionalization of biomaterial surfaces: strategies for immobilization and visualization. Polymers. 2011;3(1):114-130.

9. Wang L, Chen J, Cai C, et al. Multi-biofunctionalization of a titanium surface with a mixture of peptides to achieve excellent antimicrobial activity and biocompatibility. J Mater Chem B. 2015;3:30-33.

10. Chen C, Li H, Kong X, Zhang S-M, Lee I-S. Immobilizing osteogenic growth peptide with and without fibronectin on a titanium surface: effects of loading methods on mesenchymal stem cell differentiation. Int J Nanomedicine. 2015;10:283-295.

11. Ito Y, Hasuda H, Sakuragi M, Tsuzuki S. Surface modification of plastic, glass and titanium by photoimmobilization of polyethylene glycol for antibiofouling. Acta Biomater. 2007;3(6):1024-1032.

12. Mojgan H, Hasuda H, Sakuragi M, Yoshida Y, Suzuki K, Ito Y. Modification of the titan surface with photoreactive gelatin to regulate cell attachment. J Biomed Mater Res. 2007;83A(4):906-914.

13. Li Y, Zhao M, Wang J, Liu K, Cai C. Biofunctionalization of a "Clickable" organic layer photochemically grafted on titanium substrates. Langmuir. 2011;27(8):4848-4856.

14. Qian S, Qiao Y, Lu X. Selective biofunctional modification of titanium implants for osteogenic and antibacterial applications. J Mater Chem B. 2014;2:7475-7487.

15. Gitelman A, Rapport H. Bifunctional designed peptides induce mineralization and binding to $\mathrm{TiO}_{2}$. Langmuir. 2014;30(16):4716-4724 .

16. Miserez A, Weaver JC, Chaudhuri O. Biological materials and molecular biomimetics - filling up the empty soft materials space for tissue engineering applications. J Mater Chem B. 2015;3:13-24.

17. Bre LP, Zheng Y, Pego AP, Wang W. Taking tissue adhesives to the future: from traditional synthetic to new biomimetic approaches. Biomater Sci. 2013;1:239-253.

18. Park KM, Park KD. Facile surface immobilization of cell adhesive peptide onto $\mathrm{TiO}_{2}$ substrate via tyrosinase-catalyzed oxidative reaction. J Mater Chem. 2011;21:15906-15908.

19. Weng YJ, Ren JR, Huang N, et al. Surface engineering of Ti-O films by photochemical immobilization of gelatin. Mater Sci Eng C Biomim Supramol Syst. 2008;28(8):1495-1500.

20. Kang J, Sakuragi M, Shibata A, et al. Immobilization of epidermal growth factor on titanium and stainless steel surfaces via dopamine treatment. Mater Sci Eng C. 2012;32(8):2552-2561.

21. Kang J, Tada S, Kitajima T, Son TI, Aigaki T, Ito Y. Immobilization of bone morphogenetic protein on DOPA- or dopamine-treated titanium surfaces to enhance osseointegration. Biomed Res Intern. 2013;2013:265980.

22. Lai M, Cai K, Zhao L, Chen X, Hou Y, Yang Z. Surface functionalization of $\mathrm{TiO}_{2}$ nanotubes with bone morphogenetic protein 2 and its synergistic effect on the differentiation of mesenchymal stem cells. Biomacromolecules. 2011;12(4):1097-1105.

23. Sakuragi M, Kitajima T, Nagamune T, Ito Y. Recombinant hBMP4 incorporated with non-canonical amino acid for binding to hydroxyapatite. Biotechnol Lett. 2011;33(9):1885-1890.

24. Park SH, Zhu L, Tada S, et al. Phosphorylated gelatin to enhance cell adhesion to titanium. Polym Int. 2014;63(9):1616-1619.

25. Kang J, Tada S, Sakuragi M, et al. An epidermal growth factor derivative with binding affinity for hydroxyapatite and titanium surfaces. Biomaterials. 2013;34(38):9747-9753.

26. Amalric J, Mutin PH, Guerrero G, Ponche A, Sotto A, Lavigne J-P. Phosphonate monolayers functionalized by silver thiolate species as antibacterial nanocoating on titanium and stainless steel. J Mater Chem. 2009;19:141-149.

27. Larsen MR, Thingholm TE, Jensen ON, Roepstorff P, Joergensen TJD. Highly selective enrichment of phosphorylated peptides from peptide mixtures using titanium dioxide microcolumns. Mol Cell Proteomics. 2005;14(1):873-886.

28. Abe Y, Okazaki Y, Hiasa K, et al. Degree of immobilization of synthetic RGDS $\left(\mathrm{PO}_{3} \mathrm{H}_{2}\right) \mathrm{PA}$ peptides on titanium surfaces. Dent Mater J. 2010; 29(6):668-672. 
29. Golub M, Lott D, Watkins EB, et al. X-ray and neutron investigation of self-assembled lipid layers on a titanium surface. Biointerphases. 2013;8:21.

30. Metoki N, Liu L, Beilis E, Eliaz N, Mandler D. Preparation and characterization of alkylphosphonic acid self-assembled monolayers on titanium alloy by chemisorption and electrochemical deposition. Langmuir. 2014;30(23):6791-6799.

31. Kanta A, Sedev R, Ralton J. The formation and stability of self-assembled monolayers of octadecylphosphonic acid on titania. Colloids Surf A: Physicochem Eng Asp. 2006;291(1-3):51-58.

32. Adden N, Gamble LJ, Castner DG, Hoffmann A, Gross G, Menzel H. Phosphonic acid monolayers for binding of bioactive molecules to titanium surface. Langmuir. 2006;22(19):8197-8204.

33. Viornery C, Chevolot Y, Léonard D, et al. Surface modification of titanium with phosphonic acid to improve bone bonding: characterization by XPS and ToF-SIMS. Langmuir. 2002;18(7):2582-2589.

34. Ito Y, Liu SQ, Imanishi Y. Enhancement of cell growth on growth factor-immobilized polymer film. Biomaterials. 1991;12(5):449-453.

35. Ito Y, Zheng J, Imanishi Y, Yonezawa K, Kasuga M. Protein-free cell culture on an artificial substrate with covalently immobilized insulin. Proc Natl Acad Sci US A. 1996;93(8):3598-3601.

36. Ito Y. Covalently immobilized biosignal molecule materials for tissue engineering. Soft Matter. 2008;4:46-56.

37. Kadengodlu PA, Hebishima T, Takeshima S, et al. Positively but not negatively charged cholesterol-recombinant human gelatins foster the cellular uptake of proteins and murine immune reactions. Int J Nanomedicine. 2012; 7:5437-5450.

38. Lim KS, Alves MH, Poole-Warren LA, Marterns PJ. Covalent incorporation of non-chemically modified gelatin into degradable PVAtyramine hydrogels. Biomaterials. 2013;34(29):7097-7105.

39. Vogt C, Xing Q, He W, Li B, Frost MC, Zhao F. Fabrication and characterization of nitric oxide-releasing nanofibrous gelatin matrix. Biomacromolecules. 2013;14(8):2521-2530.

40. Yang X, Zhu L, Tada S, et al. Mussel-inspired human gelatin nanocoating for creating biologically adhesive surfaces. Int J Nanomedicine. 2014;9(1):2753-2765.
41. Kunishima M, Kawachi C, Hioki K, Terao K, Tani S. Formation of carboxamides by direct condensation of carboxylic acids and amines in alcohols using a new alcohol- and water-soluble condensing agent: DMT-MM. Tetrahedron. 2001;57(8):1551-1558.

42. Kunishima M, Kawachi C, Iwasaki F, Terao K, Tani S. Synthesis and characterization of 4-(4,6-dimethoxy-1,3,5,-triazin-2-yl)-4-methylmorpholinium chloride. Tetrahedron Lett. 1999;40(29):5327-5330.

43. Nur Azira T, Amin I, Che Man YB. Differentiation of bovine and porcine gelatins in processed products via sodium dodecyl sulphate-polyacrylamide gel electrophoresis (SDS-PAGE) and principal component analysis (PCA) techniques. Int Food Res J. 2012;19(3):1175-1180.

44. Ito Y, Hasuda H, Yamauchi T, Komatsu N, Ikebuchi K. Immobilization of erythropoietin to culture erythropoietin-dependent human leukemia cell line. Biomaterials. 2004;25(12):2293-2298.

45. Son TI, Sakuragi M, Takahashi S, et al. Visible light-induced crosslinkable gelatin. Acta Biomater. 2010;10(6):4005-4010.

46. Sannigrahi P, Ingall E. Polyphosphates as a source of enhanced P fluxes in marine sediments overlain by anoxic waters: Evidence from ${ }^{31} \mathrm{P}$ NMR. Geochem Trans. 2005;3(6):52-59.

47. Gopal R, Park JS, Seo CH, Park Y. Applications of circular dichroism for structural analysis of gelatin and antimicrobial peptides. Int $\mathrm{J} \mathrm{Mol}$ Sci. 2012;13(3):3229-3244.

48. Zhang Z, Li G, Shi B. Physicochemical properties of collagen, gelatin and collagen hydrolysate derived from bovine limed split wastes. $J$ Soc Leather Technol Chem. 2006;90:23-28.

49. Leuenberger BH. Investigation of viscosity and gelatin properties of different mammalian and fish gelatin. Food Hydrocoll. 1991;5:353-361.

50. Hotchkiss PJ, Jones SC, Paniagua SA, et al. The modification of indium tin oxide with phosphonic acids: mechanism of binding, tuning of surface properties, and potential for use in organic electronic applications. Acc Chem Res. 2012;45:337-346.

51. Hou LX, Peck Y, Wang XW, Wang DA. Surface patterning and modification of polyurethane biomaterials using silsesquioxane-gelatin additives for improved endothelial affinity. Sci China Chem. 2014;57:596-604.

52. Ikada Y. Surface modification of biomedical polymers. Macromol Symp. 1996;101:455-462.
International Journal of Nanomedicine

\section{Publish your work in this journal}

The International Journal of Nanomedicine is an international, peerreviewed journal focusing on the application of nanotechnology in diagnostics, therapeutics, and drug delivery systems throughout the biomedical field. This journal is indexed on PubMed Central,

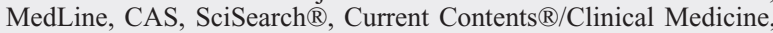

\section{Dovepress}

Journal Citation Reports/Science Edition, EMBase, Scopus and the Elsevier Bibliographic databases. The manuscript management system is completely online and includes a very quick and fair peer-review system, which is all easy to use. Visit http://www.dovepress.com/ testimonials.php to read real quotes from published authors. 